\title{
An audit of hysterectomies: indications, complications and clinico pathological analysis of hysterectomy specimens in a tertiary care center
}

\section{Vanithamani Sivapragasam $^{1 *}$, Chellammal K. Rengasamy ${ }^{1}$, Aruna B. Patil ${ }^{2}$}

\author{
${ }^{1}$ Department of Obstetrics and Gynecology, ${ }^{2}$ Department of Community Medicine, ESIC Medical College and \\ PGIMSR, Chennai, Tamil Nadu, India
}

Received: 02 July 2018

Accepted: 27 July 2018

\section{*Correspondence:}

Dr. Vanithamani Sivapragasam,

E-mail: vanithashivashankar@gmail.com

Copyright: (c) the author(s), publisher and licensee Medip Academy. This is an open-access article distributed under the terms of the Creative Commons Attribution Non-Commercial License, which permits unrestricted non-commercial use, distribution, and reproduction in any medium, provided the original work is properly cited.

\begin{abstract}
Background: Hysterectomy is the commonest major surgical procedure performed in gynecology. It is an effective treatment option for many gynecological conditions. Aim and objective of the study was to analyse the indications, complications of hysterectomies and to see whether preoperative clinical diagnosis was confirmed by histopathology. Methods: Authors present a retrospective study of 198 hysterectomised cases over a period of one year from January 2016 to December 2016. The data regarding patients age, parity, indication for hysterectomy, type of hysterectomy, complications during and after surgery and final histopathological diagnosis were collected from the records and analysed.

Results: A total of 198 cases of hysterectomies were studied. Hysterectomies were distributed over a wide age ranging from 32 years to 75 years. Most common age group was 41-50 years. Majority were done through abdominal route 162 cases (81\%). Most common indication was abnormal uterine bleeding $56(28 \%)$ and fibroid 41 (21\%). One case of accidental bladder injury was noted. Most common postoperative complication was fever (23\%). Most common histopathological lesion was fibroid $101(51 \%)$. In three cases preoperative clinical diagnosis did not correlate with final histopathological diagnosis.

Conclusions: As any surgical procedure, hysterectomy is also associated with risk of complications. Hence the indication should be carefully evaluated. Reporting of all hysterectomies should be made mandatory and audit results should be used for improvement of quality of health service. Newer and less invasive treatment options should be offered to women with benign pathologies. This will further reduce the incidence of hysterectomy.
\end{abstract}

Keywords: Complications, Hysterectomy, Histopathology, Indications

\section{INTRODUCTION}

Hysterectomy is the removal of uterus and it is the commonest major surgical procedure performed in gynecology. ${ }^{1}$ It can be done by abdominal or vaginal route and with help of laparoscopy. Hysterectomy is the effective treatment option for many conditions like fibroid, abnormal uterine bleeding, endometriosis, adenomyosis, uterine prolapse, pelvic inflammatory disease and in some cases of genital tract malignancies. ${ }^{2}$ Lifetime risk of hysterectomy ranges from $30-40 \% .{ }^{3}$ Rate of hysterectomy vary with geographic area, patient expectations, training and practice patterns of local gynecological surgeons.

Although hysterectomy is the definitive treatment for many conditions, it is not risk free. It is associated with risk of iatrogenic premature menopause, surgical and 
anesthetic complications. Hence an audit is mandatory to evaluate the indications of hysterectomy. Also, histopathological analysis of hysterectomy specimens is mandatory for diagnostic purposes, to plan postoperative treatment and to assess the pattern of lesions common in uterus and adnexae, in a particular population.

Authors present a retrospective study where one-year data of all hysterectomy cases were reviewed. Data were analysed to find out indications, complications and correlation between preoperative clinical diagnosis and final histopathological report.

Spectrum of histopathological changes encountered in these specimens were analysed to know the common lesions of uterus and adnexae in the study population.

\section{METHODS}

This study involved all patients who underwent hysterectomy at ESIC Medical College and PGIMSR, Chennai, Tamil Nadu, a teaching hospital in southern India, over a period of one year from 1st January 2016 to 31st December 2016. The study was approved by Institutional Ethical Committee board.

Case records were collected from medical records department. Patients were identified by medical record tracking.

\section{Inclusion criteria}

- All cases of abdominal and vaginal hysterectomies were included.

- Abdominal hysterectomies included total abdominal hysterectomy (TAH), total abdominal hysterectomy with unilateral salphingo oophorectomy (TAH, USO), total abdominal hysterectomy with bilateral salphingo oophorectomy (TAH, BSO) and hysterectomy done as a part of staging laparotomy.

- Vaginal hysterectomy included vaginal hysterectomy with pelvic floor repair (VH with PFR) for uterovaginal prolapse.
- Vaginal hysterectomy without pelvic floor repair (VH) and non-descent vaginal hysterectomy done for indications other than uterovaginal prolapse (NDVH).

\section{Exclusion criteria}

- Caesarean hysterectomy.

Case records then were reviewed to collect information of patient characteristics like age, parity, indication for surgery, type of hysterectomy, intraoperative complications, perioperative blood transfusion, postoperative complications.

At the end final postoperative histopathological diagnosis was recorded. Preoperative clinical diagnosis was compared with final postoperative histopathological report.

The histopathological findings of endometrium, myometrium, cervix, ovaries and fallopian tubes were recorded.

\section{Statistical analysis}

Categorical data were presented as numbers and percentages. The Chi square test was used to find an association between age group and parity, age group and types of hysterectomy. Statistical significance was assumed at $\mathrm{p}<0.05$.

The analyses were performed using SPSS statistical software (version 18.0; SPSS, Chicago, IL, USA). The graphics were provided by Microsoft Excel Software.

\section{RESULTS}

A total of 198 hysterectomies were studied. Hysterectomies were distributed from 32 years to 75 years. Most common age group underwent hysterectomy was 41-50 years, followed by age group 31-40 years.

Table 1: Distribution of various types of hysterectomy in different age groups.

\begin{tabular}{|c|c|c|c|c|c|c|c|c|c|c|}
\hline \multirow{2}{*}{$\begin{array}{l}\text { Age } \\
\text { group } \\
\text { (years) }\end{array}$} & \multicolumn{8}{|c|}{ Types of Hysterectomy } & \multicolumn{2}{|c|}{ Chi-Square Tests } \\
\hline & TAH & $\begin{array}{l}\text { TAH, } \\
\text { USO }\end{array}$ & $\begin{array}{l}\text { TAH, } \\
\text { BSO }\end{array}$ & VH & VH, PFR & NDVH & $\begin{array}{l}\text { Staging } \\
\text { laparotomy }\end{array}$ & Total & $\begin{array}{l}\text { Value, } \\
\text { df }\end{array}$ & p value \\
\hline $31-40$ & $\begin{array}{l}15 \\
(25 \%)\end{array}$ & $\begin{array}{l}24 \\
(40 \%)\end{array}$ & $\begin{array}{l}17 \\
(28 \%)\end{array}$ & $\begin{array}{l}2 \\
(3 \%)\end{array}$ & $2(3 \%)$ & 0 & $1(1 \%)$ & $61(100 \%)$ & \multirow{5}{*}{$\begin{array}{l}134.47 \\
24\end{array}$} & \multirow{5}{*}{$0.0001 * * *$} \\
\hline $41-50$ & $5(5 \%)$ & $\begin{array}{l}11 \\
(11 \%)\end{array}$ & $\begin{array}{l}75 \\
(72 \%)\end{array}$ & 0 & $9(9 \%)$ & $3(3 \%)$ & $1(1 \%)$ & $104(100 \%)$ & & \\
\hline $51-60$ & 0 & 0 & $10(44 \%)$ & $2(9 \%)$ & $10(44 \%)$ & 0 & $1(4 \%)$ & $23(100 \%)$ & & \\
\hline$>60$ & 0 & 0 & $\begin{array}{l}1 \\
(10 \%)\end{array}$ & 0 & $8(80 \%)$ & 0 & $1(10 \%)$ & $10(100 \%)$ & & \\
\hline Total & $\begin{array}{l}20 \\
(10 \%)\end{array}$ & $\begin{array}{l}35 \\
(18 \%)\end{array}$ & $\begin{array}{l}103 \\
(52 \%)\end{array}$ & $\begin{array}{l}4 \\
(2 \%)\end{array}$ & $\begin{array}{l}29 \\
(14.5 \%)\end{array}$ & $\begin{array}{l}3 \\
(1.5 \%)\end{array}$ & $4(2 \%)$ & $198(100 \%)$ & & \\
\hline
\end{tabular}

*** Highly significant 
In 31-40 years age group TAH, USO was commonly done. In 41-50 years age group TAH, BSO was commonly done. In 51-60 years, age group, TAH, BSO and VH, PFR were equally common. VH, PFR was commonly done ( $80 \%$ of the VH, PFR) in age group more than 60 years (Table 1). Majority of the women who underwent hysterectomy were parous women. Most of them were with para 2 and were in the age group of $41-50$ years $(62 \%)$.

Five patients were nulliparous, out of them four cases were between 41-50 years. One patient was 37 years old, unmarried, with intra operative finding of huge fundal fibroid distorting the anatomy; hence proceeded with hysterectomy (Table 2).

Table 2: Association between age and parity.

\begin{tabular}{|c|c|c|c|c|c|c|c|c|}
\hline \multirow{2}{*}{$\begin{array}{l}\text { Age } \\
\text { group } \\
\text { (years) }\end{array}$} & \multicolumn{6}{|l|}{ Parity } & \multicolumn{2}{|c|}{ Chi-Square Tests } \\
\hline & 1 & 2 & 3 & 4 & nulliparous & Total & Value, df & p value \\
\hline $31-40$ & $5(8 \%)$ & $40(66 \%)$ & $13(21 \%)$ & $2(3 \%)$ & $1(2 \%)$ & $61(100 \%)$ & \multirow{5}{*}{73.883} & \multirow{5}{*}{$0.0001 * * *$} \\
\hline $41-50$ & $4(4 \%)$ & $65(62 \%)$ & $25(24 \%)$ & $6(6 \%)$ & $4(4 \%)$ & $104(100 \%)$ & & \\
\hline $51-60$ & 0 & $10(44 \%)$ & $1(4 \%)$ & $12(52 \%)$ & 0 & $23(100 \%)$ & & \\
\hline$>60$ & $1(10 \%)$ & 0 & $2(20 \%)$ & $7(70 \%)$ & 0 & $10(100 \%)$ & & \\
\hline Total & $10(5 \%)$ & $115(58 \%)$ & $41(21 \%)$ & $27(14 \%)$ & $5(2 \%)$ & $198(100 \%)$ & & \\
\hline
\end{tabular}

*** Highly significant

Majority of hysterectomies were done through abdominal route, 162 cases $(82 \%)$. Remaining 36 cases were done by vaginal route. Among abdominal hysterectomies, Total abdominal hysterectomy with bilateral salphingo oophorectomy was found common, 103 cases (52\%). Total abdominal hysterectomy with unilateral salphingo oophorectomy was done in 35 cases $(18 \%)$. Vaginal hysterectomy with pelvic floor repair was done in 29 cases $(15 \%)$. Vaginal hysterectomy without pelvic floor repair was done in 2 cases.

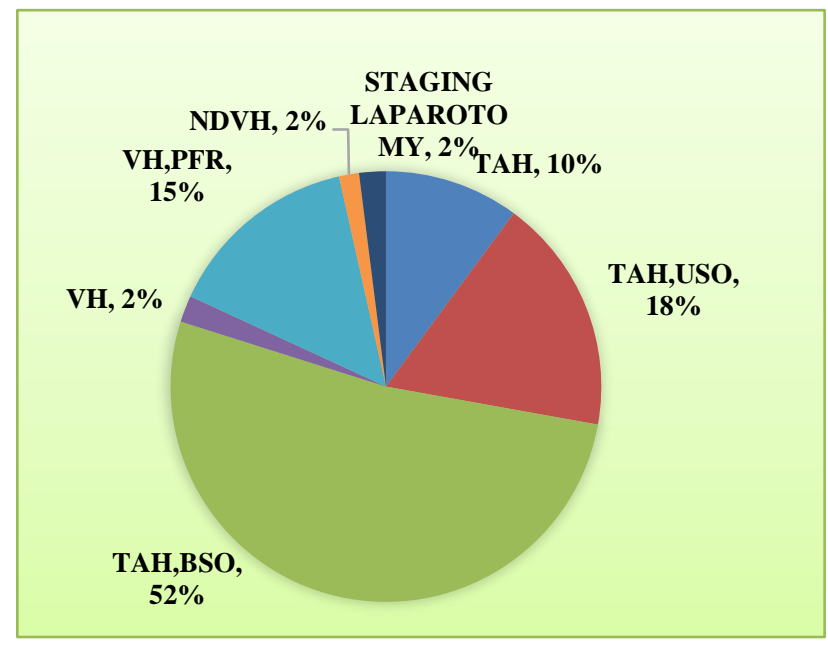

Figure 1: Proportions of types of hysterectomy.

Nondescent vaginal hysterectomy was done in 3 cases. Hysterctomy as a part of staging laparotomy was performed in 4 cases (Figure 1).
Abnormal uterine bleeding was found to be the most common indication for hysterectomy (28\%), followed by fibroid. Other common indications were abnormal uterine bleeding with fibroid and uterovaginal prolapse (Figure 2).

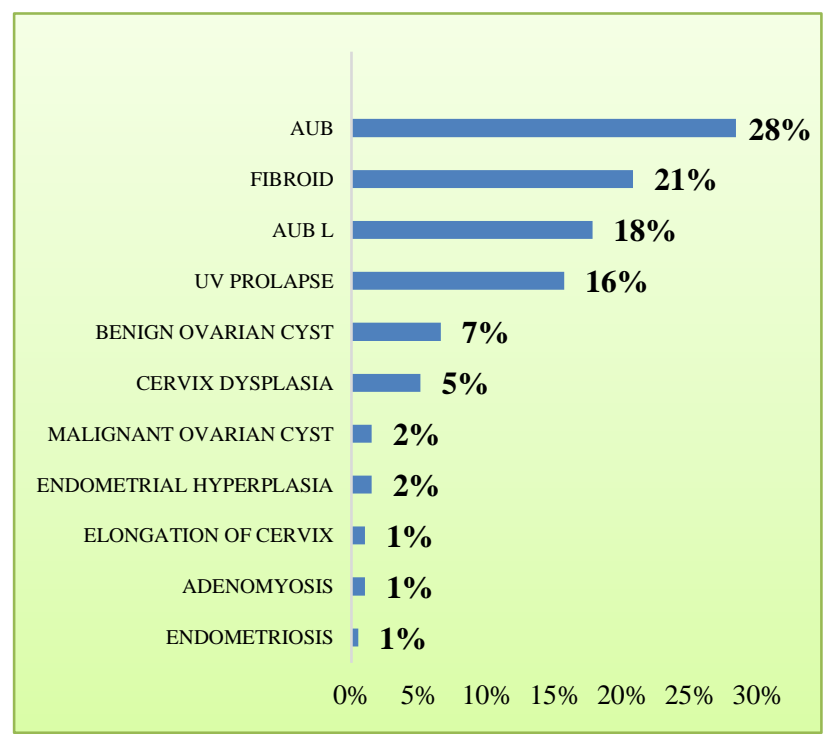

Figure 2: Indications of hysterectomy.

Bladder was accidentally injured in one case of abdominal hysterectomy. Perioperative blood transfusion

was given in 28 cases $(15 \%)$. Postoperative period was uneventful in 139 cases $(70 \%)$. Remaining 59 patients developed various complications after hysterectomy. Most common postoperative complication was fever, 46 cases $(23 \%)$. Other postoperative complications were, 
wound infection in 9 cases and wound gaping requiring secondary suturing in 4 cases.

Histopathological reports of all hysterectomy specimens were analysed. Myometrium was found to be unremarkable in $34 \%$ of the cases. Most common myometrial pathology encountered was leiomyoma in 101 cases $(51 \%)$. Adenomyosis was noted in 29 cases (Figure 3). Proliferative endometrium was the commonest pattern noted in endometrium of all hysterectomised specimens (41\%). Next common type was secretory endometrium (25\%). Atrophic endometrium was noted in $18 \%$ cases. Endometrial polyp was noted in 7 cases and endometrial hyperplasia in 7 cases (Figure 4). Nonspecific chronic cervicitis was the most common pathological change noted in ectocervix (85\%). Cervical dysplasia was encountered in 13 cases $(7 \%)$ (Figure 5).

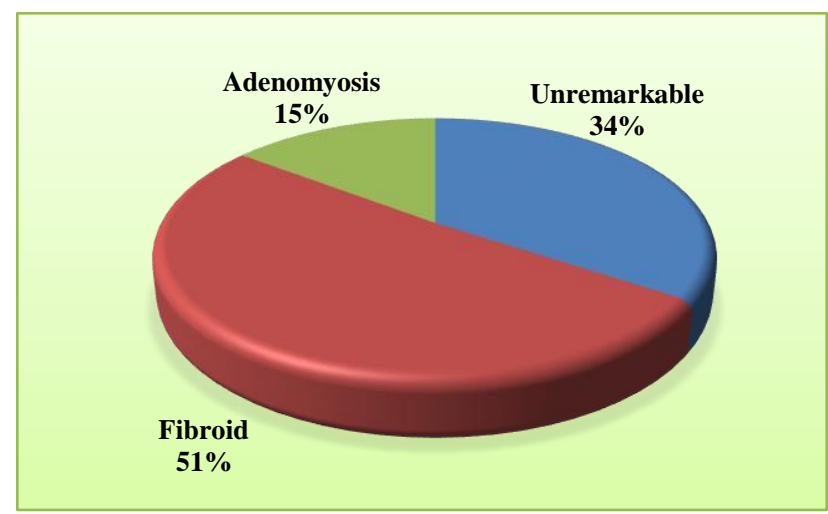

Figure 3: Histopathology of myometrium.

Histopathology of endocervix was unremarkable in $79 \%$ of the cases. Squamous metaplasia was noted in $20 \%$ cases. One case of papillary endocervicitis and one case of adenocarcinoma insitu were noted (Figure 6).

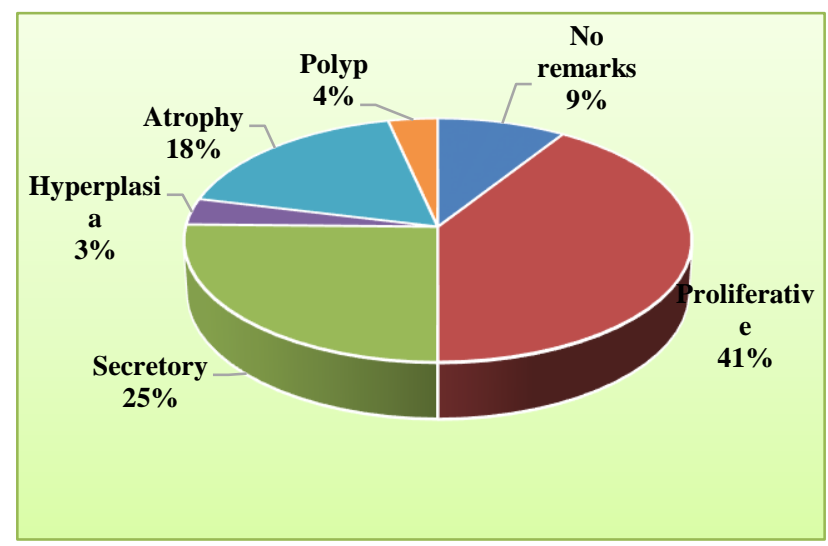

Figure 4: Histopathology of endometrium.

Histopathology of ovaries were unremarkable in $62 \%$ of the cases. Benign cystic lesions included follicular cyst (45 cases), corpus luteal cyst (11 cases), hemorrhagic cyst ( 5 cases). There were 6 cases of serous cystadenoma, 2 cases of mucinous cystadenoma and one case of teratoma. Authors observed one case of serous cystadeno carcinoma, one case of clear cell carcinoma and one case of sexcord stromal cell tumour- fibroma type (Figure 7).

Histopathology of fallopian tubes were unremarkable in majority of the cases $(91 \%)$.

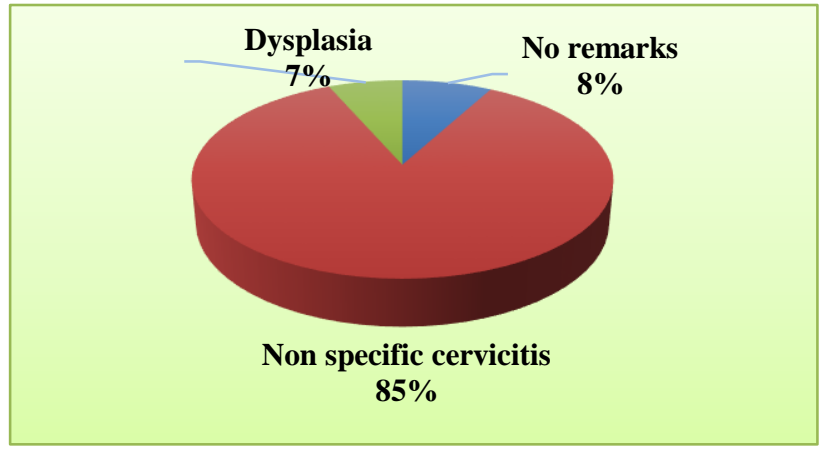

Figure 5: Histopathology of Ecto Cervix.

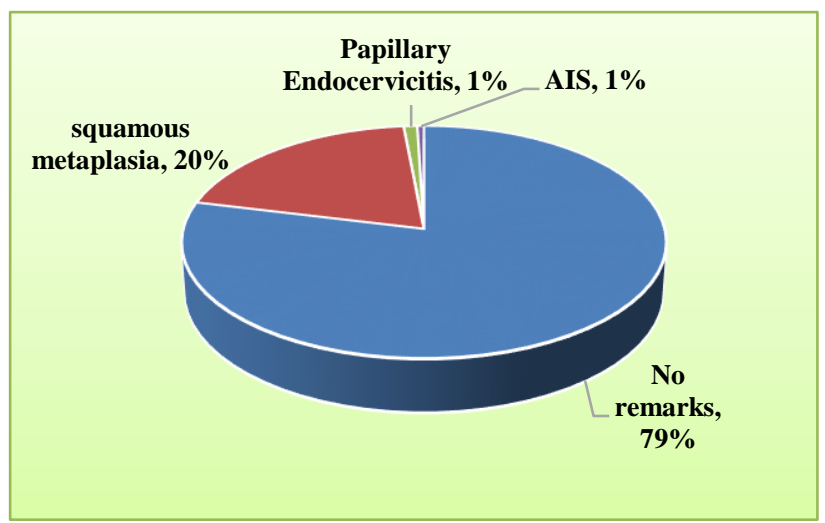

Figure 6: Histopathology of Endo cervix.

Out of 198 cases preoperative clinical diagnosis correlated with final histopathology reports in 195 cases (98\%). In three cases the preoperative clinical diagnosis and postoperative diagnosis were different.

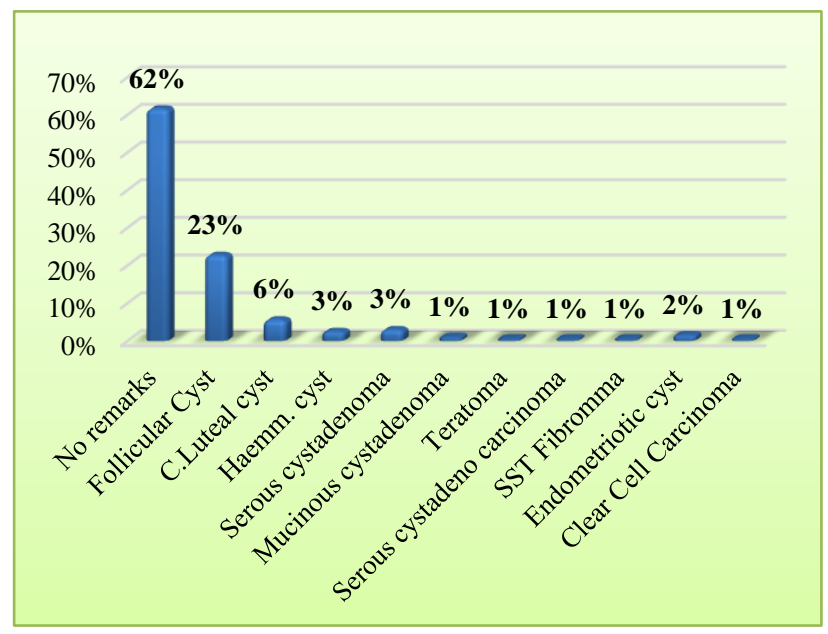

Figure 7: Histopathology of Ovary. 


\section{DISCUSSION}

Hysterectomy is the most common gynecological surgery performed worldwide as it provides definitive treatment to wide range of gynecological diseases, both benign and malignant. The indications to perform this major surgery should always be justified and the pathology should be proved histopathologically. This is so because that hysterectomy is a major surgery which has its own physical, economical, emotional, sexual and medical significance to the women. Histopathological analysis and review are mandatory to evaluate the appropriateness of the hysterectomy.

In this study 198 hysterectomies were done during the study period of one year. Age of the patient studied in this particular study ranged from 32 years to 75 years. Most common age group was 41-50 years. Similar age group was observed in other studies conducted by Saravana A et al, Perveen $\mathrm{S}$ et al, Medhi $\mathrm{P}$ et al, Domblae $\mathrm{V}$ et al, Patil $\mathrm{H}$ et al, Sharma $\mathrm{C}$ et al. ${ }^{2-7}$ Most of the cases were parous women, majority were with para 2 . This was similar to studies conducted by Saravana A et al. ${ }^{2}$

Most common route of hysterectomy was abdominal route. This was comparable to other studies conducted by Verma D et al, Domblae V et al, Sharma C et al. ${ }^{1,5,7}$

Most common type of hysterectomy done was total abdominal hysterectomy with bilateral salphingo oophorectomy. Similar observation was made in studies conducted by Verma D et al, Patil $\mathrm{H}$ et al, Sharma C et al. ${ }^{1,6,7}$

Most common indication was abnormal uterine bleeding. This is comparable to studies conducted by Perveen $\mathrm{S}$ et al and Sharma $\mathrm{C}$ et al. ${ }^{3,7}$ Next common indication was leiomyoma. Third common indication was abnormal uterine bleeding with leiomyoma. Other indications were uterovaginal prolapse in 31 cases $(16 \%)$, benign ovarian cyst in 13 cases $(7 \%)$, cervical dysplasia in 10 cases $(5 \%)$.

Intra operative period was uneventful in all cases except one patient had bladder injury. That patient was multiparous lady, case of two previous caesareans, with 28 weeks size symptomatic fibroid uterus, proceeded with abdominal hysterectomy. There was adhesion between the uterus and bladder, and bladder was injured accidentally during dissection. It was identified immediately, and repair was done by urologist. In a study conducted by Pandey D et al, bladder was injured accidentally in four cases out of 394 abdominal hysterectomies $(1 \%){ }^{8} 28$ cases $(15 \%)$ required one or two units of pack cell transfusion during the perioperative period. Most common postoperative complication observed was fever (23\%). Similar observation was made in study conducted by Khan $\mathrm{R}$ et al. ${ }^{9}$ Wound infection was noted in 9 cases and wound gaping requiring secondary suturing was noted in 4 cases.
Histopathology of myometrium was unremarkable in 68 cases $(34 \%)$. Leiomyoma $(51 \%)$ and adenomyosis $(15 \%)$ were the most frequent encountered pathologies. This was comparable to studies conducted by Verma D et al, Saravana A et al, Medhi P et al, Domblae V et al, Sharma $\mathrm{C}$ et al, Tiwana KT et al. ${ }^{1,2,4,5,7,10}$ Histopathology of endometrium was unremarkable in 18 cases $(9 \%)$. Commonly noted was proliferative endometrium, 81 cases $(41 \%)$. This was comparable to studies conducted by Verma $\mathrm{D}$ et al, Patil H et al, Sharma $\mathrm{C}$ et al. .,6,7 $^{1}$

Chronic cervicitis was the most common pathological change noted in ectocervix $(86 \%)$. This was comparable to study conducted by Verma $\mathrm{D}$ et al, Medhi $\mathrm{P}$ et al, Domblae V et al, Patil $\mathrm{H}$ et al. ${ }^{1,4-6}$ Cervical dysplasia was noted in 13 cases $(7 \%)$, out of which 10 cases were diagnosed by histopathology as dysplasia during preoperative evaluation. One case of cervical adenocarcinoma insitu was noted in histopathological analysis of endocervix.

Histopathology of ovaries were unremarkable in $62 \%$ cases. Benign cystic lesions included follicular cyst (45 cases), corpus luteal cyst (11 cases), hemorrhagic cyst (5 cases). There were 6 cases of serous cystadenoma, 2 cases of mucinous cystadenoma and one case of teratoma. Authors observed one case of serous cystadeno carcinoma, one case of clear cell carcinoma and one case of sexcord stromal cell tumour- fibroma type. Histopathology of fallopian tubes were unremarkable in majority of the cases $(91 \%)$.

Histopathological analysis correlated well with preoperative clinical diagnosis in majority of the cases. Pre-operative clinical diagnosis did not correlate with final diagnosis in the following three cases. Case 1preoperative diagnosis was benign ovarian cyst and all tumour markers CA 125, CEA, LDH, AFP, $\beta$ HCG were normal; final histopathology was clear cell carcinoma. Case 2- preoperative diagnosis after imaging was broad ligament fibroid; intra operative findings were suggestive of parietal wall granuloma with pedunculated subserous fibroid; The final report of suspected granuloma came as organising abscess due to inflammatory pathology. Case 3- pre-operative diagnosis was cervical dysplasia for which hysterectomy was done. Final histopathology report was adenocarcinoma in situ of endocervix.

\section{CONCLUSION}

This study concludes that as any surgical procedure, hysterectomy is also associated with complications during and after surgery. Therefore, the indication for hysterectomy should be carefully evaluated. Hence reporting of all hysterectomies should be made mandatory so that the audit results can be used for improvement in the quality of health services. Ideally, newer and lesser invasive treatment options like levonorgestrel intrauterine system, endometrial ablation, operative hysteroscopy and laparoscopy should be 
offered to women with benign pathologies. This will further reduce the incidence of hysterectomy. However, lack of awareness of patients, poor patient compliance, poverty, inability to attend regular health care facilities, absence of regular follow up, lack of latest equipments and technical skill are major hurdles in providing ideal standard of care in these women. This study also signifies the fact that the histopathological analysis of the hysterectomy specimens should be a mandatory procedure, even if the gross appearance is normal, because a few lesions are found to be incidental finding. It may even harbour a focus of malignancy.

Histopathological analysis also provides a correlation with clinical and postoperative diagnosis and guides appropriate management in the postoperative period. Justification of the hysterectomy is also proved when the histopathological diagnosis corresponds with the preoperative diagnosis.

\section{ACKNOWLEDGMENTS}

Authors would like to thank department of Pathology, department of Medical Records for their support during study.

Funding: No funding sources Conflict of interest: None declared

Ethical approval: The study was approved by the Institutional Ethics Committee

\section{REFERENCES}

1. Verma D, Singh P, Kulshrestha R. Analysis of histopathological examination of the hysterectomy specimens in a north Indian teaching institute. Int $\mathbf{J}$ Res Med Sci. 2016 Dec;4(11):4753-8.

2. Saravana A, Patil SB, Patil SS. Clinicopathological study of hysterectomised specimens. Int J Reprod Contracept Obstet Gynecol. 2016 Dec 20;6(1):246-8.
3. Perveen S, Ansari A, Naheed F, Sultana A. Pattern of lesion in hysterectomy specimens and clinical correlation. Pak J Med H S 2014; 8(2): 465-8.

4. Medhi P, Dowerah S, Borgohain D. A histopathological audit of hysterectomy: experience at a tertiary care teaching hospital. Int $\mathbf{J}$ Contemp Med Res. 2016;3(4):1226-8.

5. Domblae V, Gundalli S, Sonali. Histopathological analysis of uterine lesions in hysterectomy specimens. Int J Sci Res. 2015;4(5):2171-4.

6. Patil HA, Patil A, Mahajan SV. Histopathological findings in uterus and cervix of hysterectomy specimens. MVP J Med Sci. 2015;2(1):26-9.

7. Sharma C, Sharma M, Raina R, Soni A, Chander B, Verma S. Gynecological diseases in rural India: A critical appraisal of indications and route of surgery along with histopathology correlation of 922 women undergoing major gynecological surgery. J Mid-life Health. 2014;5(2):55.

8. Pandey D, Sehgal K, Saxena A, Hebbar S, Nambiar J, Bhat RG. An audit of indications, complications, and justification of hysterectomies at a teaching hospital in India. Int J Reprod Med. 2014;2014.

9. Khan R, Sultana H. How does Histopathology correlate with clinical and operative findings in abdominal hysterectomy?. J Armed Forces Med Coll Bangladesh. 2010 Dec;6(2):17-20.

10. Tiwana KK, Nibhoria S, Monga $T$, Phutela R. Histopathological audit of 373 non-oncological hysterectomies in a teaching hospital. Pathol Res Int. 2014;2014:1-5.

Cite this article as: Sivapragasam V, Rengasamy CK, Patil AB. An audit of hysterectomies: indications, complications and clinico pathological analysis of hysterectomy specimens in a tertiary care center. Int J Reprod Contracept Obstet Gynecol 2018;7:3689-94. 